\title{
44352 - LOCAL ANESTHETIC INFILTRATION REDUCES OPIOID USE AFTER APPENDECTOMY
}

\section{Belliveau Marc, Département d'anesthésiologie, Université de Montréal, Montréal, QC, Canada; \\ Juraj Istvan, Département d'anesthésiologie, Université de Montréal; \\ François Donati, Département d'anesthésiologie, Université de Montréal;}

INTRODUCTION: Among the various measures that have been proposed to reduce opioid requirements after appendectomy, one finds: laparoscopic surgery(1), wound infiltration with a local anesthetic (2), use of acetaminophen and non-steroidal anti-inflammatory drugs (NSAIDs), and absence of perforation. The purpose of this study was to examine the importance of each of these factors.

METHODS: After Ethics Committee approval, a 1-yr retrospective study was conducted on patients who underwent appendectomy in a teaching hospital. Information was manually retrieved from patients' charts to obtain standard demographic data, duration of anesthesia, length of hospital stay, surgical approach, wound infiltration, status of appendicitis, opioid and non-opioid analgesics received from admission until surgery and for $24 \mathrm{hr}$ after surgery. Opioid doses were converted to parenteral morphine equivalents. Multiple linear regression was applied to determine if surgical approach, wound infiltration, perforation of the appendix, use of NSAIDs or administration of acetaminophen altered opioid consumption. Statistically significant differences were considered to be present when $\mathrm{P}<0.05$.

RESULTS: There were 250 cases (150 males and 100 females). Patient age was $29.5 \pm 18.6 \mathrm{yr}$. Mean opioid consumption in the $24 \mathrm{hr}$ following surgery was $13.2 \pm 12.9 \mathrm{mg}$ morphine equivalents. Wound infiltration with bupivacaine was associated with a significant decrease in analgesic requirements (Table). Most (90.4\%) patients received acetaminophen and this was associated with decreased opioid requirements. No statistically significant decrease in opioid consumption was observed with NSAIDs. With a laparoscopic technique, anesthesia time was longer ( $93 \pm 30$ vs $62 \pm 21 \mathrm{~min} ; \mathrm{P}<0.001$ ), but opioid requirements were not diminished significantly. Perforation of the appendix ( $30 \%$ of cases), increased hospital stay ( $6.4 \pm 3.9$ vs $2.7 \pm 2.3$ days), but was not associated with a greater opioid consumption (Table). 


\section{Table. Influence of five factors on opioid consumption in the first $24 \mathrm{hr}$ after appendectomy.}

\begin{tabular}{|l|c|c|c|}
\hline Intervention & $\begin{array}{c}\text { Number } \\
\text { of } \\
\text { cases }\end{array}$ & $\begin{array}{c}\text { Opioid use } \\
\text { (mg morphine equivalent) } \\
\text { (mean } \pm \text { SD) }\end{array}$ & $P$ \\
\hline Infiltration with LA & 179 & $11.5 \pm 10.4$ & \multirow{2}{*}{0.006} \\
\hline No infiltration with LA & 71 & $17.6 \pm 17.2$ & \multirow{2}{*}{0.040} \\
\hline \hline Acetaminophen & 226 & $12.4 \pm 11.9$ & \multirow{2}{*}{0.391} \\
\hline No acetaminophen & 24 & $20.9 \pm 18.6$ & \multirow{2}{*}{0.319} \\
\hline NSAIDs & 167 & $12.1 \pm 12.6$ & \\
\hline \hline No NSAIDs & 83 & $15.5 \pm 13.4$ & \\
\hline Laparoscopy & 62 & $11.6 \pm 11.3$ & 128 \\
\hline \hline Simple & 188 & $13.8 \pm 13.4$ & $12.2 \pm 11.3$ \\
\cline { 1 - 3 } Perforated & 176 & $16.7 \pm 16.3$ & \\
\hline
\end{tabular}

LA: local anesthetic; NSAIDs : non-steroidal anti-inflammatory drugs.

CONCLUSION: Opioid requirements after appendectomy are relatively modest. Wound infiltration with bupivacaine and administration of acetaminophen appear to be effective morphine-sparing measures. Addition of NSAIDs did not seem effective, probably because opioid use was low. A laparoscopic technique takes longer to perform without benefit on opioid requirements or duration of hospital stay.

REFERENCES:

1. FRAZEE R et al. Ann Surg 1994; 219(723

2. ONG CKS et al. Anesth\&Analg 2005; 100; 757. 